\title{
Design and Realization of a Bi-directional DC / DC Converter in photovoltaic power system
}

\author{
GuoQin Zhang ${ }^{1, \text { a }}$, YongJun Dai ${ }^{2, b}$, JiaMin Cui ${ }^{3, c}$
}

${ }^{1}$ Zhejiang University of Water Resources and Electric Power, Hangzhou, Zhejiang, China 310018

${ }^{2}$ Zhejiang JEC New Energy Technology Co., Ltd

${ }^{3}$ Zhejiang University of Water Resources and Electric Power, Hangzhou, Zhejiang, China

azhgq@zjweu.edu.cn, bdaiyj@jec.com.cn, ㄷ1610594@qq.com

Keywords: photovoltaic power, DC/DC, controller

Abstract: A energy storage device is essential in photovoltaic power system. The battery charge and discharge is a typical bidirectional DC / DC converter. According to design requirements, Buck/Boost DC/DC has been selected as the main circuit topology. The parameters of components have been set. The method of the double closed loop is designed and ensures the converter stable and efficient. The converter is realized and shows the accuracy of the design and the reliability of the control.

\section{Introduction}

The use of new energy is urgent with the emergence of the extreme weather. Solar energy is inexhaustible and renewable. It is clean, safe and maintenance-free. It plays an important role in the long-term energy strategy. The solar power is mainly composed of the solar cell array, accumulator battery, the controller and the DC/AC inverter. The solar cell array is used as the conversion of solar energy into electrical energy. The battery is used as storing electrical energy. The battery stores energy in sunny days and discharges energy in bad weather. The controller is to control the charge and discharge, the current protection, voltage protection, etc. The inverter changes the DC power come from the solar cell array into AC power the user can directly use.

The application of solar photovoltaic power generation system has three forms: the grid-connected system, the off-grid system and hybrid blending photovoltaic system. For example, the off-grid system is shown in Fig.1.

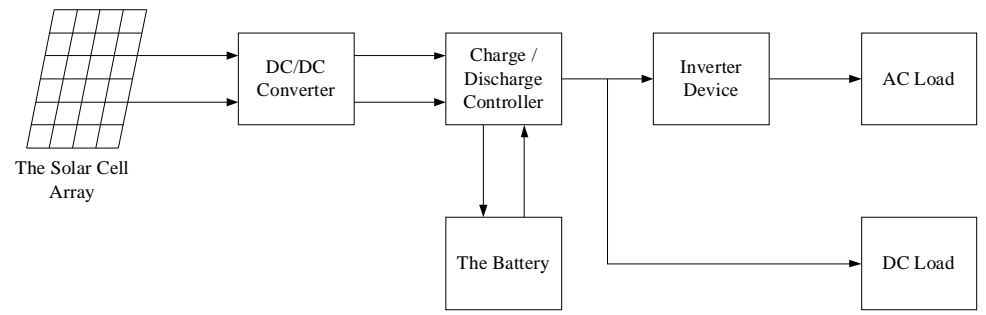

Fig.1 The block diagram of off-grid photovoltaic power generation system

The energy exchange of the battery is essential in the off-grid and grid connected systems including the hybrid blending system. In other words, the bi-directional DC/DC converter is necessary. 


\section{Selection of main circuit}

The design requirements of the bi-directional DC/DC converter in energy storage system are as follows: the output power $P_{0}=30(\mathrm{~kW})$, the input voltage( DC side ) $U_{1}=400(\mathrm{~V})$, the output voltage $U_{2}=750(\mathrm{~V})$, the frequency of the switching elements $f_{s}=20(\mathrm{kHZ})$, the ripple voltage is less than $1 \%$.

According to whether there is isolation between input and output, the bi-directional DC/DC converters can be divided into isolated and non isolated DC/DC converters. The isolated types include forward bi-directional DC/DC converter, flyback bi-directional full bridge DC/DC bi-directional push-pull DC/DC converter [1]. The non isolated bi-directional DC/DC converters are: bidirectional Buck/Boost DC/DC converter, bi-directional DC/DC Cuk converter, bi-directional Sepic-Zeta DC/DC converter, etc [2].

Isolation refers to inserting high frequency transformers in the input and output. Therefore, the isolated bi-directional DC/DC converter is generally applicable for occasions of the high-power or electrical isolation. Non isolated bi-directional DC/DC converters are transformerless, small volume, light weight, low loss and low price. And non isolated bi-directional DC/DC converters can meet the design requirements. So we choose the non isolated bi-directional DC/DC converters in this design. The voltage and current stress was compared in various non isolated bi-directional DC/DC converters [3, 4].

The bidirectional Cuk DC/DC and Sepic-Zeta converters need two inductors with large inductance, which increases the volume and the cost of the energy storage device. The bi-directional Buck/boost only need one inductor. And we has accumulated some experience in the Buck/boost DC/DC converter. So we choose the bidirectional Buck/Boost DC/DC converter as the energy storage system in the photovoltaic power system. Its topology is shown in fig.2.

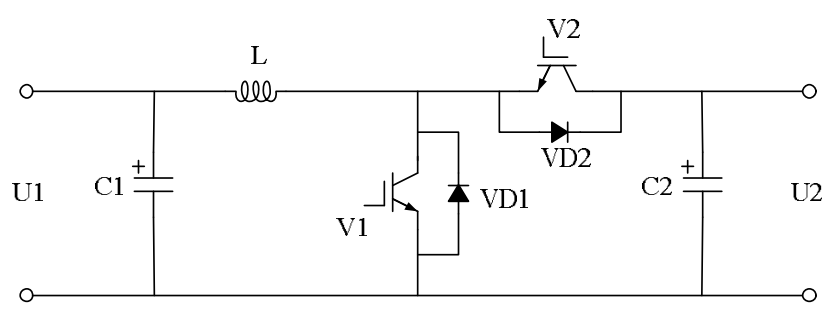

Fig. 2 The topology of Buck/Boost bi-directional converter

The switches V1 and V2 are complementary, which guarantees that the current of the inductor L is continuous in the whole process. When the V1 works and V2 doesn't work, the circuit works in the Boost mode. The circuit can be equivalent to fig.3.

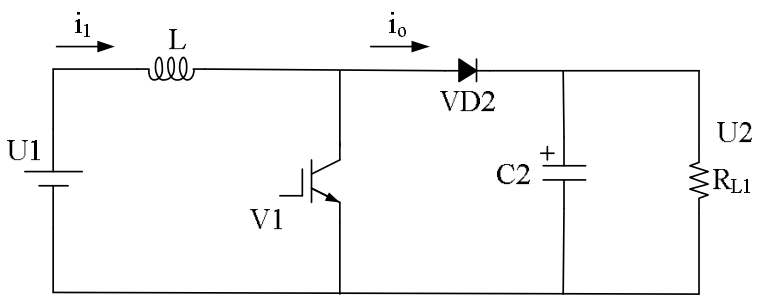

Fig. 3 The circuit works in the Boost state

When the controllable switch V1 is in the turn-on state, the inductor L stores energy. The current is about Ii. when the switch V1 is in the turn-off state, the capacitor C is charged by $\mathrm{U} 2$ and $\mathrm{L}$. In the meanwhile $\mathrm{U} 2$ and $\mathrm{L}$ provide energy to the load $\mathrm{R}_{\mathrm{L} 1}$.

When the switch V1 doesn't work and the V2 works, the circuit works in the Buck mode. The 
circuit can be equivalent to fig. 4 .

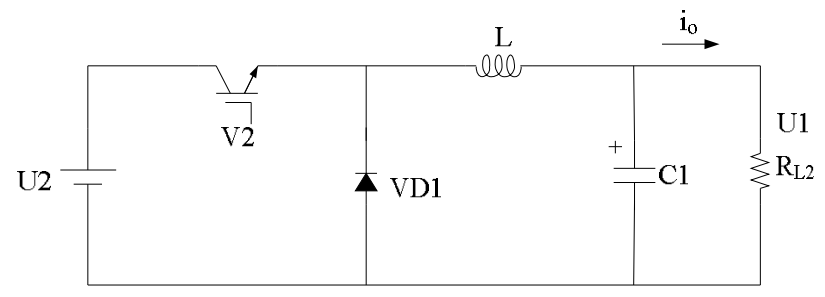

Fig. 4 The circuit works in the Buck state

When the V2 is in the turn-on state, the power U2 supplies the energy to the load $\mathrm{R}_{\mathrm{L} 2}$. U1=U2 and the load current Io is increased exponentially. When the V2 is in a turn-off state, the current flows through the diode VD1 and approximately U1=0. And the load current is decreased exponentially.

\section{Design of parameters}

Selection of power devices. In power devices, IGBT is widely used in high frequency switching devices and power electronics equipments. It has advantages of MOSFET and GTR. It has high switch frequency, high input impedance, small switch loss and so on. It is suitable for high voltage, large current and high power, especially for the switching its frequency is greater than 1kHZ. IGBT was chosen as switching elements in the Buck/Boost bi-directional converter. According to the main topology (fig.2), the maximum voltage and current in theory can be determined. And then selected the actual rated voltage and current of the IGBT.

The analysis in selection of main circuit shows that the maximum current through the IGBT is equal to that through the inductor L. Ignoring the ripple current, the maximum current through the IGBT is about:

$I_{s}=\frac{P_{0}}{U_{1}}=\frac{30 \times 10^{3}}{400}=75(A)$

Consideration of 2 times allowance, $I_{s}=150(A)$

The maximum voltage of the IGBT is that of output.

$V_{C E \max }=750(V)$

Taking into account the overload, the voltage spike caused by the switching and other factors, the voltage stress of the IGBT should be greater than $750 \mathrm{~V}$.

Based on the above consideration of the current and voltage of IGBT, the CM150DY-24H model of Mitsubishi Co. is selected. The module has two units IGBT, the maximum collector current is $150 \mathrm{~A}$. the maximum voltage between collector and emitter is $1200 \mathrm{~V}$.

Selection of the inductor The inductor in the bi-directional DC/DC converter is designed according to the working mode of the circuit (CCM or DCM) and the demand of the current ripple. When the DC/DC works in the Buck CCM (fig.4) and the inductor ripple current can be expressed as[5]:

$$
\Delta I=\frac{D_{2} U_{2}\left(1-D_{2}\right)}{f_{s} L}
$$


In the Eq.1, D2 is the duty cycle. $D_{2}=\frac{U_{1}}{U_{2}}=\frac{400}{750}=0.53$

From the Eq.1, we can get:

$$
L=\frac{D_{2} U_{2}\left(1-D_{2}\right)}{f_{s} \Delta I}
$$

In Eq.2: $\mathrm{U} 2=750 \mathrm{~V}, \mathrm{D}_{2}=0.53, f_{s}=20 k$

When the DC/DC works in the Boost CCM (fig.3) and the inductor ripple current can be expressed as[5]:

$$
\Delta I=\frac{U_{1} D_{1}}{f_{s} L}
$$

From the Eq.3, we can get:

$$
L=\frac{U_{1} D_{1}}{f_{s} \Delta I}
$$

$\mathrm{D}_{1}$ is the duty cycle in the Boost mode. $D_{1}=1-\frac{U_{1}}{U_{2}}=0.47$

According to Eq.1 and Eq.3, we can get:

$$
\Delta I=\frac{D_{2} U_{2}\left(1-D_{2}\right)}{f_{s} L}=\frac{U_{1} D_{1}}{f_{s} L} .
$$

According to the engineering experience, the half of the current ripple through the inductor is selected as the $30 \%$ of the rated current. We can get the minimum inductance. That is:

$$
\frac{\Delta I}{2}=0.3 I_{s}=0.3 \frac{P_{o}}{U_{1}} .
$$

We plug Eq. 6 into Eq.2 or Eq.4:

$$
L=\frac{U_{1}}{0.6 \frac{P_{o}}{U_{1}} f_{s}}\left(1-\frac{U_{1}}{U_{2}}\right)=\frac{400}{0.6 \times \frac{30 \times 10^{3}}{400} \times 20 \times 10^{3}}\left(1-\frac{400}{750}\right)=208.8 \times 10^{-6}(F)=208.8(\mu F)
$$

Consideration of some allowance, we decide $L=300(\mu F)$

Selection of filter capacitors. According to the design requirements, the voltage ripple should be less than 1\%, in the Buck CCM, the capacitor ripple voltage is[5]:

$$
\begin{aligned}
& \Delta v_{c}=\frac{D_{2} U_{2}\left(1-D_{2}\right)}{8 f_{s}^{2} L C_{1}} \text { We can get: } \\
& C_{1}=\frac{D_{2} U_{2}\left(1-D_{2}\right)}{8 f_{s}^{2} L \Delta v_{c}}=\frac{0.53 \times 750 \times(1-0.53)}{8 \times\left(20 \times 10^{3}\right)^{2} \times 300 \times 10^{-6} \times 400 \times 1 \%}=48.6 \times 10^{-6} \mathrm{~F}=48.6(\mu \mathrm{F})
\end{aligned}
$$

The SHF-1200-60 model of EACO co. is selected. It is the film capacitor .The maximum voltage is 
$1200 \mathrm{~V}$ and the capacitance is $60 \mu F$.

In the Boost CCM, the capacitor ripple voltage is:

$$
\Delta v_{c}=\frac{I_{01} D_{1}}{f_{s} C}
$$

We can get:

$$
C=\frac{I_{01} D_{1}}{f_{s} \Delta v_{c}}=\frac{\frac{P_{o}}{U_{2}} D_{1}}{f_{s} \Delta v_{c}}=\frac{40 \times 0.47}{20 \times 10^{3} \times 750 \times 1 \%}=125 \times 10^{-6}(F)=125(\mu F)
$$

The SHF-1500-68 model of EACO co. is selected. It is the film capacitor. The maximum voltage is $1500 \mathrm{~V}$ and the capacitance is $68 \mu F$. Two capacitors in parallel can meet the design requirements.

\section{Controller of the Buck/Boost converter}

The controller of the converter can reasonably control the working state. It can reduce the ripple of the current and voltage in the input or output and can improve the efficiency of the converter. The single closed-loop cannot achieve the stability of the bi-directional DC/DC converter. Double closed-loop is the basic controller. We use the voltage and current double closed-loop as shown in fig.5.

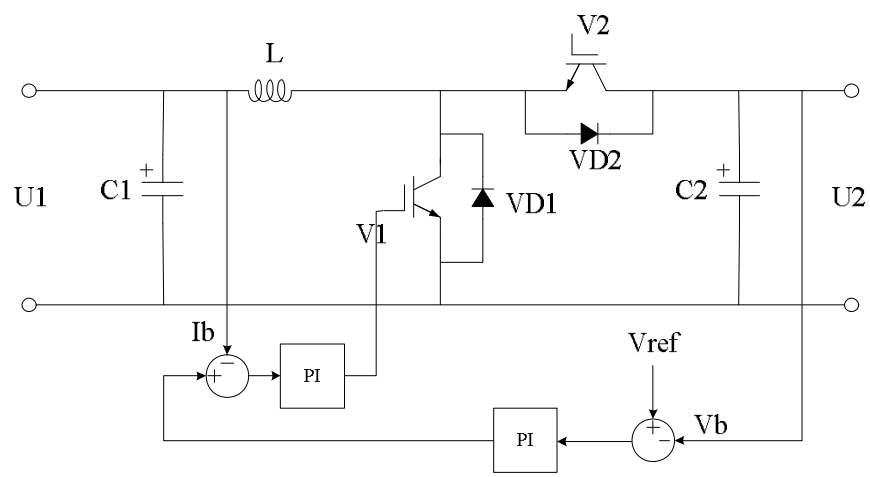

Fig. 5 the voltage and current double closed-loop controller

Control system includes the outer voltage loop and inner current loop. In outer voltage loop, we get the $\mathrm{Vb}$ and compare with $\mathrm{V}_{\text {ref. }}$ The difference between two is sent to the PI regulator. And then enter into the current loop. Finally comparing with $\mathrm{I}_{\mathrm{b}}$, the difference through by the other PI regulator into the PWM modulation. The controller can get the stable voltage in U2 side and the stable current in U1 side.

\section{Conclusions}

The main circuit is selected and parameters of components is designed in the circuit by analysis. The controller is decided by comparison. The DC/DC is presented according to the design. The test verifies that it realizes all the specifications required by the design purpose.

\section{Acknowledgements}

This work was financially supported by the National High-Tech R\&D Program(863 Program), 
project number 2014 AA052005.

\section{References}

[1] Yibin Tong, Tong Wu, Xinmin Jin et al. Research on the topology of the bidirectional DC/DC converter $[\mathrm{J}]$. proceedings of the Chinese Journal of electrical and mechanical engineering, 2007, 27 (13):P. 81-86.

[2] Xueqing Chen, Junlai Huang. Application and circuit topology of bidirectional DC/DC converter [J]. popular science and technology, 2008, (10): P.48-50.

[3] Xin fan. Research on high power bidirectional DC/DC converter for hybrid bus [D]. Harbin: Harbin Institute of Technology, 2009:14-15.

[4] Junhui Wu, Shenghua Huang. Application in hybrid electric vehicle (HEV) three-level bidirectional DC / DC converter [J]. Motor technology, 2006, (2): P.23-25.

[5] Simon Ang Alejandro, Oliva switching power converter - switching power supply principle, simulation and design (Third Edition), 2014:P.13-28. 